\title{
A REELEIÇÃO DE EDUARDO PAES PARA A PREFEITURA DO RJ: IDENTIFICANDO DISCURSOS, POSIÇÕES E ESCOLHAS ADOTADAS NA CAMPANHA ELEITORAL ${ }^{1}$
}

Isabel Cristina Veloso de Oliveira ${ }^{2}$

\begin{abstract}
Resumo
O resultado das eleições de 2012 para o cargo de prefeito do Rio de Janeiro não trouxe qualquer surpresa. A vitória do candidato Eduardo Paes (PMDB) foi prevista por todos os institutos de pesquisa, e foi favorecida por estratégias de marketing que demandam atenção da Ciência Política. $O$ principal objetivo deste artigo é identificar algumas posições e escolhas adotadas na campanha eleitoral, com enfoque em questões midiáticas, que ajudem a explicar o sucesso nas urnas obtido pelo candidato, apresentando, através de análise de conteúdo, algumas estratégias que foram implementadas e fatores que contribuíram para consolidar a vitória. Dois principais argumentos serão explorados: a disparidade na distribuição do tempo de TV entre os candidatos, devido à ampla coligação do candidato Eduardo Paes, e a estratégia central do candidato de utilizar esse tempo de TV para relacionar sua imagem a um bom governo.
\end{abstract}

Palavras-chave: Eleições; Rio de Janeiro; Prefeitura; Eduardo Paes.

\begin{abstract}
The outcome of the 2012 Rio de Janeiro City mayoral elections did not bring any surprise. The victory of the candidate Eduardo Paes (PMDB) was predicted by all research institutes, and was favored by marketing strategies that demand the attention of Political Science. This article's main purpose is to identify some choices and positions taken during the campaign trail, focusing on media issues, to help explain the electoral success achieved by the candidate, presenting, through content analysis, some strategies that have been implemented and factors that contributed to consolidate the victory. Two main supporting arguments will be explored: the disparity in the TV time distribution among the candidates due to the broad coalition held by the candidate Eduardo Paes, and the candidate's core strategy of using this TV time to relate his image to a good government.
\end{abstract}

Keywords: Elections; Rio de Janeiro; City Hall; Eduardo Paes.

\section{Resumen}

El resultado de las elecciones de 2012 para el cargo de alcalde de Río de Janeiro no trajo ninguna sorpresa. La victoria del candidato Eduardo Paes (PMDB) fue predicha por los institutos de investigación, y fue favorecida por estrategias de marketing que deben ser estudiadas por las ciencias políticas. El propósito de este artículo es identificar algunas posiciones y decisiones tomadas en la campaña electoral, centrando la atención en lo mediatico, lo cual ayuda a explicar el éxito electoral del candidato, a través de análisis de contenido, así como algunas de las estrategias que se han implementado y los factores que contribuyeron a consolidar la victoria. Dos argumentos son explorados: la disparidad en la distribución del tiempo de televisión entre los candidatos, debido a la amplia coalición del candidato Eduardo Paes, y la estrategia central de utilizar el tiempo al aire para relacionar su imagen con la de un buen gobierno.

Palabras-clave: Elecciones; Rio de Janeiro; Alcaldía; Eduardo Paes.

\footnotetext{
${ }^{1}$ DOI deste artigo: $10.5380 /$ recp.v6i1.41958.

2 Mestre em Ciência Política (IESP-UERJ) e Doutoranda em Ciência Política (IESP-UERJ). Bolsista de doutorado da Coordenação de Aperfeiçoamento de Pessoal de Nível Superior (CAPES). E-mail: isabelveloso.pol@gmail.com.
} 


\section{INTRODUÇÃO}

Desde o início das pesquisas a reeleição de Eduardo Paes (PMDB) parecia garantida, sua coligação contou com 20 legendas: PMDB, PT, PP, PDT, PTB, PSB, PPS, PSC, PCdoB, PRB, PRP, PMN, PSL, PTC, PSDC, PT do B, PHS, PSD, PTN e PRTB. Oito candidatos participaram do pleito: Antonio Carlos (PCO), Aspásia Camargo (PV), Cyro Garcia (PSTU), Eduardo Paes (PMDB), Fernando Siqueira (PPL), Marcelo Freixo (PSOL), Otávio Leite (PSDB) e Rodrigo Maia (DEM). Eduardo Paes apareceu como favorito em todas as pesquisas realizadas durante a campanha eleitoral ${ }^{3}$. A vitória foi alcançada ainda em primeiro turno com o total de 2.097 .733 votos, 64,6\% dos votos válidos, a votação mais expressiva da história recente das eleições municipais do Rio de Janeiro ${ }^{4}$.

Diversas variáveis podem contribuir para uma reeleição, como: desenvolvimento econômico e social apresentado no município em questão, as políticas públicas que foram adotadas, o modo como o candidato atendeu às demandas de sua base eleitoral, a forma como sua atuação foi apresentada pela mídia, as estratégias de marketing de sua equipe de campanha, entre outros. Em todo esse processo, os meios de comunicação têm um papel fundamental, pois informam o eleitor, de maneira mais ou menos imparcial, e ajudam a formar a imagem dos candidatos e a definir a opinião do eleitor. Nesse ponto, analisar a disparidade do tempo de campanha de TV dos candidatos à prefeitura do Rio de Janeiro e o uso que foi feito desse tempo torna-se um fator fundamental para analisar o processo de reeleição de Eduardo Paes, e esse será nosso principal enfoque.

\section{REGRAS ELEITORAIS}

Antes de discorrer acerca do ocorrido nas eleições municipais de 2012 da cidade do Rio de Janeiro, esse tópico tratará de regras eleitorais fundamentais para a compreensão da distribuição do tempo entre os candidatos, no Horário Gratuito de Propaganda Eleitoral (HGPE) e nas inserções de TV e rádio e de outras regras que podem ter influenciado no resultado das eleições.

\footnotetext{
${ }^{3}$ Ver anexo 1 e anexo 2.

4 Todos os dados que serão apresentados e analisados nesse artigo foram cedidos pelo Laboratório de Estudos Eleitorais, em Comunicação Política e Opinião Pública, vinculado ao Instituto de Estudos Sociais e Políticos da Universidade do Estado do Rio de Janeiro (IESP-UERJ). O DOXA elaborou um árduo trabalho de gravação acompanhamento, transcrição e organização de um banco de dados sobre as eleições de 2012. Ao instituto, sobretudo ao Prof. Dr. Felipe Borba, todo o meu agradecimento. http://doxa.iesp.uerj.br/
} 
O HGPE tem duração de 45 dias. Nas eleições para Prefeito e Vice-Prefeito a propaganda é exibida nas segundas, quartas e sextas ${ }^{5}$. Os horários são distribuídos entre todos os partidos e coligações que lançarem candidatura e que tiverem representação na Câmara dos Deputados, a distribuição é feita da seguinte forma:

\begin{abstract}
I - um terço, igualitariamente (independentemente de representação na Câmara); II - dois terços, proporcionalmente ao número de representantes na Câmara dos Deputados, considerado, no caso de coligação, o resultado da soma do número de representantes de todos os partidos que a integram (TSE, Lei ${ }^{\circ} 9.504$, de 30/09/1997, Art. 47, \ $2^{\circ}$ ).
\end{abstract}

A mesma regra de distribuição de tempo é válida para as propagandas e inserções no rádio e na TV. Quanto às inserções, as emissoras de televisão e rádio, bem como os canais por assinatura, em casos mencionados no artigo 57, deverão reservar 30 minutos diários da programação para a veiculação de inserções que podem ser de 15, 30 ou 60 segundos, conforme a opção de distribuição do tempo feita por cada partido ou coligação. As inserções são exibidas entre oito e vinte e quatro horas, ao longo da programação das emissoras “(...) a distribuição levará em conta os blocos de audiência entre as oito e as doze horas, as doze e às dezoito horas, as dezoito e as vinte e uma horas, as vinte e uma e as vinte e quatro horas" (TSE, 2012, Art. 51, \ III).

A transmissão da propaganda eleitoral do Rio de Janeiro ficou a cargo da TV Globo, pois, de acordo com o critério utilizado pelo TRE-RJ, as emissoras são designadas através da associação entre a audiência da emissora e o tamanho do eleitorado de cada municípió ${ }^{6}$

Quanto às inserções, não é permitido utilizar gravações externas, animações, efeitos especiais, montagens ou mensagens que possam ridicularizar a imagem de um candidato, partido ou coligação.

A transmissão de debates por emissoras de rádio ou televisão é facultativa, porém, caso seja realizado um ou mais debates, é assegurada a participação de todos os candidatos de partidos que possuem representação na Câmara dos Deputados, a participação dos demais candidatos é facultativa, ficando a decisão a cargo da emissora. Nas eleições majoritárias os

\footnotetext{
5 “a) das sete horas às sete horas e trinta minutos e das doze horas às doze horas e trinta minutos, no rádio; b) das treze horas às treze horas e trinta minutos e das vinte horas e trinta minutos às vinte e uma horas, na televisão".

${ }^{6}$ No ano de 2012, “[o] TRE-RJ também determinou que a propaganda eleitoral do município do Rio de Janeiro também seria transmitida nos canais a cabo NGT, MTV e TV Câmara" Disponível em: http://agenciabrasil.ebc.com.br/noticia/2012-08-14/tre-do-rio-de-janeiro-define-regra-de-transmissao-dohorario-eleitoral-gratuito-nas-emissoras-de-tv. Acesso em 07/02/2013.
} 
debates podem ser feito em conjunto, estando presentes todos os candidatos ao cargo eletivo ou em grupo de, no mínimo, três candidatos (TSE, 2012, art. 46).

A propaganda veiculada na mídia tem um peso cada vez mais relevante devido a proibições impostas recentemente pelo Tribunal Superior Eleitoral (TSE). Dentre essas proibições estão:

$\int 6^{\circ}$ É vedada na campanha eleitoral a confecção, utilização, distribuição por comitê, candidato, ou com a sua autorização, de camisetas, chaveiros, bonés, canetas, brindes, cestas básicas ou quaisquer outros bens ou materiais que possam proporcionar vantagem ao eleitor.

$\int 8^{\circ}$ É vedada a propaganda eleitoral mediante outdoors, sujeitando-se a empresa responsável, os partidos, coligações e candidatos à imediata retirada da propaganda irregular e ao pagamento de multa no valor de 5.000 (cinco mil) a 15.000 (quinze mil) UFIRs (TSE, Lei nº 9.504, de 30/09/1997, Art. 39).

$\mathrm{Na}$ internet a propaganda pode ser feita na página do candidato, mediante comunicado prévio do endereço eletrônico à Justiça Eleitoral, sendo o endereço eletrônico hospedado em um provedor estabelecido no Brasil. É permitido o envio de mensagens eletrônicas para endereços previamente cadastrados e a propaganda por meio de blogs, redes sociais e sítios de mensagens instantâneas (TSE, Lei no 9.504, de 30/09/1997, Art. 57), porém, é vedado qualquer tipo de propaganda eleitoral paga (idem).

Também é proibida a realização de showmício e de eventos semelhantes voltados para a promoção de um determinado candidato, sendo também proibida a apresentação de artistas, mesmo não remunerados, para animar comícios e reuniões eleitorais (Art. 39, $\int 7^{\circ}$ ).

\section{ELEIÇÕES MUNICIPAIS DO RIO DE JANEIRO: A CONSTRUÇÃO DO CANDIDATO EDUARDO PAES}

Em 2008 Eduardo Paes alcançou sua primeira vitória para o cargo de prefeito do Rio de Janeiro, na ocasião o candidato Eduardo Paes estava com 38 anos. Formado em direito pela PUC-Rio, iniciou sua carreira política aos 23 anos, na época, Paes era filiado ao PV e, durante o governo de César Maia (1993-1996), atuou como subprefeito da Barra da Tijuca e Jacarepaguá. Em 1996 se transferiu para o PFL e foi eleito vereador com 83.418 votos, maior votação obtida no pleito de 1996 da cidade do Rio de Janeiro (TRE-RJ, 1996). Paes atuou também como secretario de Meio Ambiente do município do Rio e secretário de Turismo, Esporte e Lazer, pelo estado durante o governo de Sérgio Cabral Filho. Neste momento, Paes estava no PSDB e havia rompido seu laço político com César Maia. Posteriormente foi convidado por Sérgio Cabral Filho a ingressar no PMDB, onde foi lançado na disputa pela prefeitura do Rio de Janeiro. 
As pesquisas realizadas pelo IBOPE durante o primeiro turno das eleições de 2008 apresentaram o seguinte panorama:

Gráfico 1 - Eleições Municipais de 2008 - Pesquisas IBOPE e resultado do $1^{\circ}$ turno

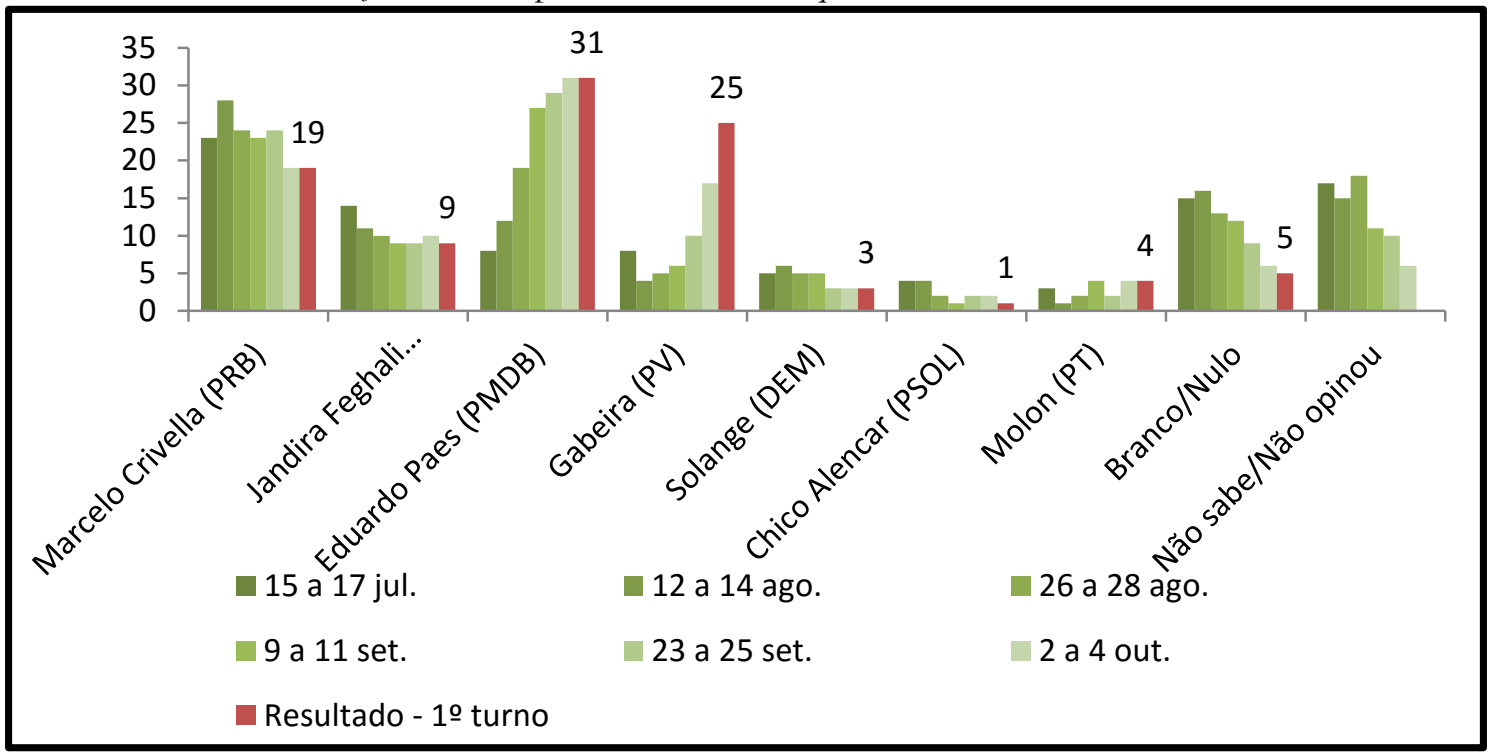

Fonte: IBOPE (2008) e TSE (2008) ${ }^{7}$

Embora tenha sido o vereador mais votado em 1996, Paes ainda era um candidato pouco conhecido entre os eleitores, sua atuação ainda não estava vinculada a uma administração bem avaliada. Antes do início do HGPE, Paes estava com 8\% das intenções de voto na primeira pesquisa realizada pelo IBOPE e 12\% na segunda pesquisa do instituto, após o início do HGPE, onde sua imagem foi amplamente ligada a gestão do governador Sérgio Cabral Filho, como sendo um dos fortalecedores e idealizadores de políticas implementadas pelo governo estadual, tal associação foi feita através do pertencimento partidário e de depoimentos do então governador. Paes subiu para 19\% na pesquisa realizada entre 26 e 28 de agosto, passando posteriormente para 27\%, no período de 9 a 11 de setembro, $29 \%$, no período entre 23 e 25 de setembro e $31 \%$ no período de 2 a 4 de outubro. Paes obteve 31\% dos votos no primeiro turno e disputou o segundo turno com Fernando Gabeira, que alcançou 25\% dos votos válidos. Ou seja, Eduardo Paes era o terceiro candidato nas intenções de voto, em empate técnico com Fernando Gabeira, e acabou alcançando a maior votação do primeiro turno.

\footnotetext{
${ }^{7}$ Também concorreram os seguintes candidatos: Paulo Ramos (PDT), Filipe Pereira (PSC), Vinicius Cordeiro (PT do B), Eduardo Serra (PCB) e Antonio Carlos (PCO). Dentre esses candidatos apenas Paulo Ramos conseguiu chegar a $1 \%$ dos votos.
} 
Eduardo Paes venceu com 50,83\% no segundo turno, um dos motivos atribuídos a esta vitória foi o elevado número de abstenções resultantes de um ponto facultativo decretado pelo governo do estado, que teria favorecido Paes. A eleição foi decidida com uma diferença de apenas 60 mil votos.

\subsection{A DISPUTA DA REELEIÇÃO EM 2012: ARGUMENTOS DE CAMPANHA EM PROL DA CONTINUIDADE DO GOVERNO}

Durante a campanha eleitoral para a reeleição de Eduardo Paes, em 2012, pode-se definir como a principal estratégia de campanha do candidato o ato de se apresentar como a única opção de continuidade de um governo bem avaliado. De acordo com o Instituto DataFolha, às vésperas das eleições de 2012, 45\% do eleitorado aprovada o governo de Eduardo Paes, 38\% consideravam uma gestão regular e apenas $15 \%$ consideravam a gestão ruim ou péssima ${ }^{8}$. Como definem FIGUEIREDO, ALDÉ, DIAS \& JORGE, “(...) os candidatos transitam, o tempo todo, entre mundos possíveis, atuais e futuros" (p.4). Para os autores, a dinâmica da disputa eleitoral faz com que cada campanha estabeleça uma estrutura discursiva que pode ser resumida em quatro pontos:

\footnotetext{
1. Descrever um mundo atual, dentre os possíveis, que melhor represente as condições sociais em que as pessoas vivem; aqui o objetivo é persuadir a todos de que "o copo com água está quase vazio ou quase cheio";

2. Descrever um mundo futuro, dentre os possíveis, desejável para a maioria do eleitorado; aqui o objetivo é persuadir as pessoas de que, no mínimo, "o copo com água não ficará quase vazio", isto é, a situação melhorará;

3. A melhor maneira de se construir o mundo futuro desejável é fazer X; e, 4. A única garantia de que $\mathrm{X}$ será feito é através do candidato, do grupo político ou do partido ao qual está ligado; esses atores se tornam os garantidores da realização do mundo futuro desejável (FIGUIREDO, ALDÉ, DIAS \& JORGE, 1998, p.4-5).
}

O argumento utilizado na retórica de Eduardo Paes é basicamente o de que no mundo atual o "copo com água" está quase cheio e que ele é o único caminho para que o "copo com água" fique completamente cheio, ou seja, para se chegar ao futuro desejável é necessária à sua permanência no governo. $\mathrm{O}$ vasto tempo disponibilizado para a propaganda eleitoral do candidato foi fundamental para o sucesso de sua estratégia central, que foi a associação de sua imagem a um bom governo. As realizações do governo foram amplamente

\footnotetext{
${ }^{8}$ Ver em: http://datafolha.folha.uol.com.br/opiniaopublica/2012/07/1130490-eduardo-paes-pmdb-lideradisputa-com-54.shtml. Acessado em 29/06/2015.
} 
divulgadas, tanto é que $83,8 \%$ das inserções veiculadas na TV se referiam a projetos e melhorias implementadas, como as que serão descritas a seguir?'

Transporte: Bus Rapid Transit (BRT), sistema de transporte coletivo operado por meio de ônibus articulados com capacidade para até 140 pessoas. O sistema reduziu em até $50 \%$ o tempo gasto no percurso entre a Barra da Tijuca e o bairro de Santa Cruz, ambos localizados na zona oeste da cidade; Bilhete Único Carioca trata-se de um cartão recarregável que pode ser adquirido sem custo e permite que o passageiro utilize duas conduções dentro de um determinado período de tempo com um custo reduzido.

Saúde: Ampliação das equipes do Programa Saúde da Família e construção de 66 novas Clínicas da Família, que oferecem atendimento médico e odontológico; Construção e reestruturação de cinco hospitais, totalizando 1.500 novos leitos; Criação do Programa Cegonha Carioca, que oferece acompanhamento personalizado de toda a gestação. A gestante cadastrada no programa recebe gratuitamente o enxoval do recém-nascido no nono mês de gestação; Criação do Programa de Atendimento ao Idoso (PADI).

Meio ambiente: Tratamento parcial do Rio Arroio Fundo; Desativação do Lixão de Gramacho e criação de um Centro de Tratamento de Resíduos em Seropédica.

Habitação e Urbanismo: Criação do Porto Maravilha, projeto de revitalização da região portuária, já em andamento, que planeja contemplar uma área total de cinco milhões de metros quadrados. Durante as escavações para uma obra de drenagem foi redescoberto o Cais do Valongo, antigo ponto de chegada e comercialização de escravos vindos do continente africano, o local foi restaurado e transformado em ponto turístico; Criação do projeto de urbanização popular Morar Carioca que planeja atender o total de 50 comunidades.

Cultura: Construção do Museu de Arte do Rio (MAR), localizado na Praça Mauá e início da construção do Museu do Amanhã, no Pier Mauá, em parceria com a Fundação Roberto Marinho e Banco Santander.

Educação: Fim do sistema de aprovação automática para os alunos da rede municipal; Implementação do Projeto Escola do Amanhã, que passou a oferecer ensino integral em 152 escolas; Criação dos Espaços de Desenvolvimento Infantil (EDIs), que abriu

\footnotetext{
9 Após o término das eleições de 2008 o Jornal O Globo publicou uma lista com 82 promessas de campanha de Eduardo Paes, o mesmo se comprometeu a cumpri-las assinando uma cópia da matéria. Segundo a avaliação do Jornal O Globo, através de consulta a documentos oficiais e visitas de fiscalização, 67\% das promessas foram cumpridas, e $14 \%$ não foram cumpridas. $17 \%$ das promessas foram parcialmente cumpridas e $2 \%$ não foram passíveis de comprovação. Matéria completa disponível em: http://oglobo.globo.com/pais/o-globofaz-balanco-das-promessas-de-eduardo-paes-6173531
} 
30 mil vagas em educação para crianças entre seis meses e seis anos de idade, instaladas em diversos pontos da cidade, principalmente na Zona Oeste.

Assistência Social: Criação do Cartão Família Carioca, programa de transferência de renda complementar ao Programa Bolsa Família, do Governo Federal. O programa contempla famílias beneficiárias do Bolsa Família que possuem filhos matriculados em escolas municipais, cujos pais participem da vida escolar dos filhos, comparecendo a reuniões e eventos e os filhos atinjam uma frequência escolar mínima de $90 \%$. O valor médio mensal recebido através do cartão é de $\mathrm{R} \$ 70,00$; Projeto Academia da Terceira Idade (ATI), instaladas em praças da cidade e criação dos Centros de Referência das Pessoas com Deficiência, que oferecem atendimento multiprofissional voltado para a saúde, lazer e qualificação profissional ${ }^{10}$.

Os projetos elencados acima foram os escolhidos pela equipe de marketing do candidato para ilustrar sua campanha e construir a associação do candidato a um bom governo. No entanto, nem sempre essas escolhas estão associadas ao que é considerado prioritário pelo eleitor, mas sim procura enaltecer o que foi construído. As pesquisas de opinião divulgadas no Brasil demonstram que o eleitor brasileiro tende a priorizar saúde, segurança e educação. Pelo fato do candidato em questão ter mais da metade de todo o tempo de HGPE disponível e ainda dispor do maior número de inserções pagas, ele pôde falar não só desses três temas, considerados prioritários para a maior parte dos eleitores, mas também de outros temas como transporte, meio ambiente, habitação e assistência social, destacando as maiores realizações do seu governo.

\section{ELEIÇÕES 2012 - ANDAMENTO DAS PESQUISAS E RESULTADO}

Tendo quase três minutos a mais de tempo de TV e rádio do que a soma do tempo de exposição de todos os seus adversários, mais recursos de campanha e mais intenções de voto que a soma de todos os seus oponentes durante todas as fases da campanha, a trajetória de Eduardo Paes não foi marcada pelos autos e baixos típicos dos pleitos majoritários. Em suas inserções na TV e rádio sua equipe optou por não fazer ataques aos oponentes. Paes se apresentou como um candidato favorito na disputa. Sua reeleição, pleiteada com o slogan "Somos um Rio", nunca esteve distante de seu horizonte. Os candidatos vencedores por zona eleitoral podem ser representados da seguinte forma:

\footnotetext{
${ }^{10}$ Informações adaptadas do site: http://www.eduardopaes.com.br/realizacoes/.
} 


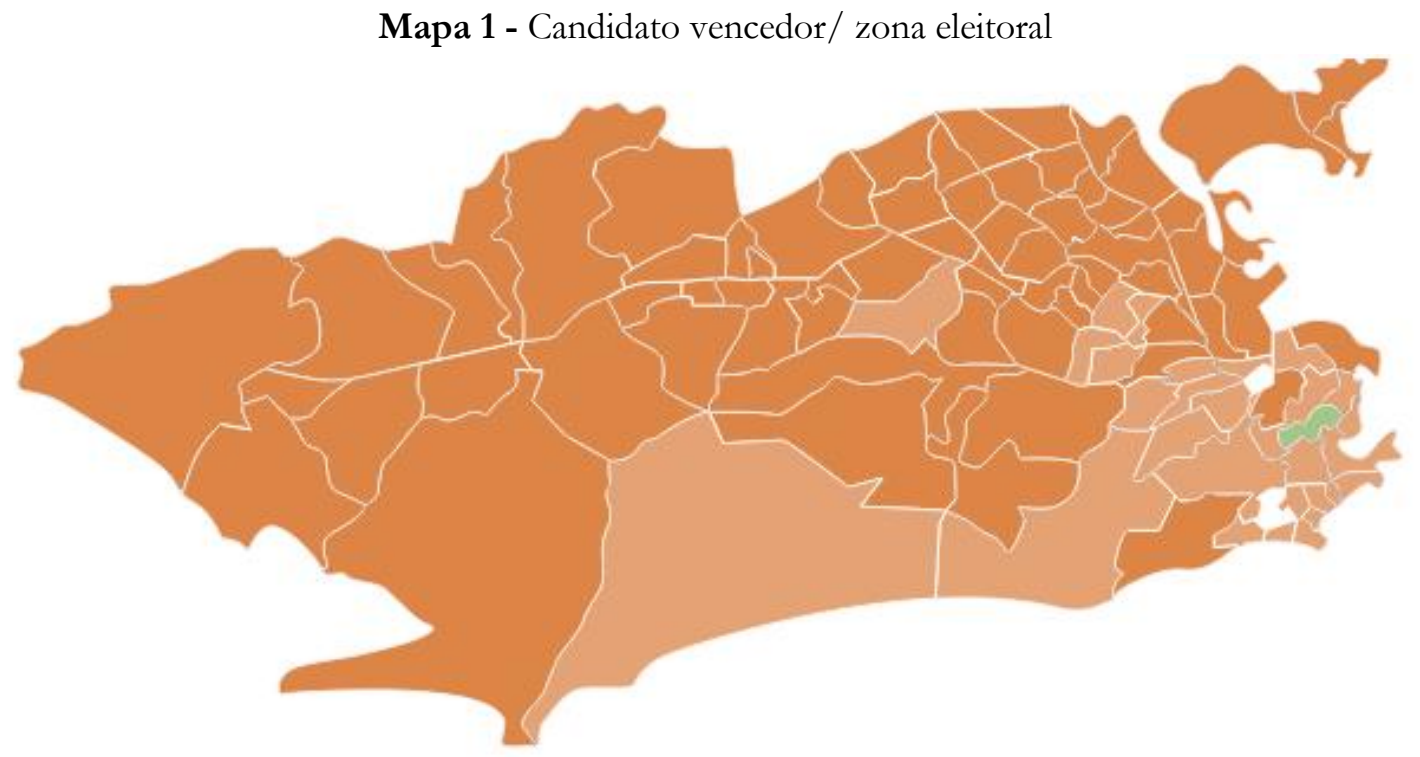

\section{Eduardo Paes - De 58,48\% até 77,77\% \\ Eduardo Paes - De 39,06\% até 58,42\% \\ Marcelo Freixo - 48,26\%}

Fonte: TSE e TER-RJ (2012) e UOL

Sem grandes surpresas, alcançando uma vitória histórica, Eduardo Paes (PMDB) venceu as eleições em primeiro turno com 64,6\% (2.097.733 votos), seguido por: Marcelo Freixo (PSOL) com 28,15 (914.082 votos), o que surpreendeu devido à escassez de tempo de TV e recursos financeiros, porém a campanha foi marcada por forte participação popular através das redes sociais; Rodrigo Maia (DEM) com 2,94 (95.328 votos), Otávio Leite (PSDB) com 2,47 (80.059 votos), Aspásia (PV) com 1,2\% (41.314 votos); Cyro Garcia (PSTU) com 0,39\% (12.596 votos); Fernando Siqueira (PPL) com 0,15\% (5.021 votos) e Antonio Carlos (PCO) com 0,03\% (937 votos). Paes venceu em quase todas as zonas eleitorais, com exceção da zona que compreende Cosme Velho e Laranjeiras, onde perdeu para Marcelo Freixo, que obteve 48,26\% contra 43,71\% de Eduardo Paes. Freixo obteve o segundo lugar em todas as zonas em que Paes foi vitorioso, os demais candidatos não ultrapassaram $6 \%$ em nenhuma das zonas.

\section{OS TEMAS MAIS RECORRENTES DAS INSERÇÕES NO RIO DE}

\section{JANEIRO}

O início do Horário Gratuito de Propaganda Eleitoral (HGPE) é, geralmente, um período que imprime novos contornos à campanha eleitoral, onde tem início a disputa e a utilização de estratégias. Como descreve Cervi (2010), o HGPE funciona como um "marcador público" de tempo e espaço que indica ao eleitor mediano o início do "tempo da 
política", sobretudo porque, atualmente, com as restrições estabelecidas pela Justiça Eleitoral que proíbem o uso de carros de som, outdoors, distribuição de bonés e camisetas e realização de comícios, restam poucos momentos para marcar o período em que o eleitor deve começar a se preocupar em escolher o seu candidato, para Cervi (2010):

(...) o HGPE marca o momento em que o eleitor precisa começar a prestar atenção, de fato, na política. Até então, as eleições fazem parte da esfera pública e não necessariamente entra na esfera privada dos cidadãos. Mobiliza as elites partidárias, os militantes políticos e simpatizantes das candidaturas desde meados de maio, pelo menos. Também mobiliza a imprensa que faz cobertura eleitoral de gabinetes, salas de reuniões e convenções com baixa ou nenhuma participação popular. No entanto, não chama a atenção do eleitor comum, aquele que definirá o resultado da disputa (CERVI, 2010, p. 12).

O HGPE e as inserções na TV e rádio são momentos oportunos para que o eleitor mediano tenha contato com as propostas dos candidatos. Devido a sua ampla coligação, Somos um Rio, composta por 20 partidos, o candidato Eduardo Paes contou com o tempo diário de TV de 16' 17" 92, tempo inferior à soma de todos os seus oponentes. O candidato Marcelo Freixo, segundo colocado nas eleições, por exemplo, pôde utilizar apenas 01' 22" 02 por dia, conforme aponta a tabela 2:

Tabela 1 - Distribuição de tempo/dia válida para HGPE e inserções na televisão e rádio (mm:ss:cc)

\begin{tabular}{c|c|c|c}
\hline \hline Partido & $\begin{array}{c}\text { Tempo } \\
\text { igualitário }\end{array}$ & Tempo proporcional & Tempo total/ dia \\
\hline PSDB & $01^{\prime} 15^{\prime \prime} 00$ & $02^{\prime} 03^{\prime \prime} 98$ & $03^{\prime} 18^{\prime \prime} 98$ \\
\hline PV & $01^{\prime} 15^{\prime \prime} 00$ & $00^{\prime} 25^{\prime \prime} 73$ & $01^{\prime} 40^{\prime \prime} 73$ \\
\hline PPL & $01^{\prime} 15^{\prime \prime} 00$ & $00^{\prime} 00^{\prime \prime} 00$ & $01^{\prime} 15^{\prime \prime} 00$ \\
\hline PCO & $01^{\prime} 15^{\prime \prime} 00$ & $00^{\prime} 00^{\prime \prime} 00$ & $01^{\prime} 15^{\prime \prime} 00$ \\
\hline PSOL & $01^{\prime} 15^{\prime \prime} 00$ & $00^{\prime} 07^{\prime \prime} 02$ & $01^{\prime} 22^{\prime \prime} 02$ \\
\hline $\begin{array}{c}\text { Um Rio melhor para os } \\
\text { cariocas (DEM e PR) }\end{array}$ & $01^{\prime} 15^{\prime \prime} 00$ & $\left(01^{\prime} 24^{\prime \prime} 21(\mathrm{PR})+00^{\prime} 56^{\prime \prime}\right.$ & $03^{\prime} 35^{\prime \prime} 35$ \\
\hline
\end{tabular}




\begin{tabular}{|c|c|c|c|}
\hline $\begin{array}{c}\text { Somos um Rio (PMDB, PT, } \\
\text { PP, PDT, PTB, PSB, PPS, } \\
\text { PSC, PCdoB, PRB, PRP, } \\
\text { PMN, PSL, PTC, PSDC, PT } \\
\text { do B, PHS, PSD, PTN e } \\
\text { PRTB). }\end{array}$ & $01^{\prime} 15^{\prime \prime} 00$ & $\begin{array}{c}\text { 15' 02" } 92 \\
(02 \text { ' 55" } 44 \text { (PMDB) + 00' } \\
46 " 78 \text { (PTB) + 03' 23" } 51 \\
\text { (PT) + 00' 53" } 80 \text { (PDT) + } \\
01^{\prime} 35^{\prime \prime} 91 \text { (PDT) + 00' 18" } \\
71 \text { (PRB) + 01' 59" } 30 \\
(\mathrm{PSD})+00^{\prime} 09^{\prime \prime} 36 \text { (PT do } \\
\text { B) + 00' 32" } 75 \text { (PCdoB). }\end{array}$ & $16^{\prime} 17^{\prime \prime} 92$ \\
\hline
\end{tabular}

Fonte: TER-RJ (2012).

Partindo de um amplo banco de dados organizado e cedido pelo Laboratório de Estudos Eleitorais, em Comunicação Política e Opinião Pública (DOXA - IESP/UERJ) ${ }^{11}$, este artigo optou por analisar todas as inserções veiculadas na TV Globo durante os 45 dias de propaganda eleitoral, pois, por estarem distribuídas ao longo de toda a programação, essas inserções alcançam um público alvo maior do que o HGPE ou os debates, quando o eleitor muitas vezes opta por não assistir. Em 2012, o Datafolha perguntou aos eleitores se haviam assistido o debate realizado na TV Globo e apenas 32\% haviam assistido, dentre esses 11\% assistiram o debate completo e 21\% assistiu apenas uma parte (DATAFOLHA, 2012).

Foram 2.761 inserções, sendo 996 exibidas pelo candidato Eduardo Paes. Foram identificados os três spots mais recorrentes de cada candidato e feita a classificação de todas as inserções em três categorias "positiva", "negativa" e "comparativa". Todos os ataques feitos nas inserções foram direcionados ao candidato da situação, o mesmo não veiculou crítica a nenhum candidato. Os ataques dos três principais oponentes de Paes foram identificados e apresentados em gráficos que demonstram os períodos em que os ataques foram mais recorrentes, com o objetivo de deixar mais evidente as estratégias adotadas por cada candidato.

\section{a) Eduardo Paes (PMDB):}

\begin{tabular}{|c|c|c|c|}
\hline Frase 1 & Assunto & Duração & Exibição \\
\hline “A filha da Fernanda vai & Educação - Criação dos & & Foi exibida 70 \\
estudar em um dos 120 & Espaços de Desenvolvimento sendo 996 \\
novos EDIs...". & Infantil (EDIs). Elogio à & 30 segundos. & o número total de \\
& gestão. & & spots do \\
& & & \\
\hline
\end{tabular}

\footnotetext{
${ }^{11}$ Para mais informações sobre o Laboratório: http://doxa.iesp.uerj.br/.
} 


\begin{tabular}{|c|c|c|c|}
\hline Frase 2 & Assunto & Duração & Exibição \\
\hline $\begin{array}{c}\text { "Você que vai hoje de Santa } \\
\text { Cruz à Barra" }\end{array}$ & $\begin{array}{c}\text { Transporte público. Criação } \\
\text { do BRT. Elogio à gestão. }\end{array}$ & 1 minuto. & vezes. \\
\hline Frase 3 & Assunto & Duração & Exibição \\
\hline "Você que hoje recebe \\
atendimento preventivo"
\end{tabular}

Fonte: DOXA 2012.

Total de exibições por tempo

\begin{tabular}{|c|c|}
\hline Tempo & Exibição \\
\hline 1 minuto & 490 \\
\hline 30 segundos & 450 \\
\hline 15 segundos & 56 \\
\hline TOTAL & 996 \\
\hline
\end{tabular}

Fonte: DOXA 2012.

b) Marcelo Freixo (PSOL)

\begin{tabular}{|c|c|c|c|}
\hline Frase 1 & Assunto & Duração & Exibição \\
\hline $\begin{array}{c}\text { "Há muito tempo o Rio de } \\
\text { Janeiro não tem um comício } \\
\text { político" }\end{array}$ & $\begin{array}{c}\text { Convocatória para } \\
\text { comício. Referência à } \\
\text { participação popular na } \\
\text { campanha de Freixo. }\end{array}$ & 30 segundos & número total de \\
spots do \\
candidato.
\end{tabular}

Fonte: DOXA 2012. 
Total de exibições por tempo

\begin{tabular}{|l|l|}
\hline Tempo & Exibição \\
\hline $\mathbf{1}$ minuto & 0 \\
\hline $\mathbf{3 0}$ segundos & 95 \\
\hline $\mathbf{1 5}$ segundos & 59 \\
\hline TOTAL & 154 \\
\hline
\end{tabular}

Fonte: DOXA 2012.

Freixo não utilizou nenhuma inserção de 1 minuto, 62\% foram de 30 segundos e $38 \%$ foram de 15 segundos. Seus ataques foram direcionados a Eduardo Paes, e se referiam principalmente à saúde e transporte. Os ataques foram concentrados na metade inicial do período de campanha. Essa organização se deu, provavelmente, pelo fato de que os ataques também geram rejeição e ao fato de que muitos eleitores valorizam mais as propostas do que as críticas a outros candidatos no momento de decidir o voto.

Gráfico 2 - Ataques de Freixo direcionados a Paes/ dia

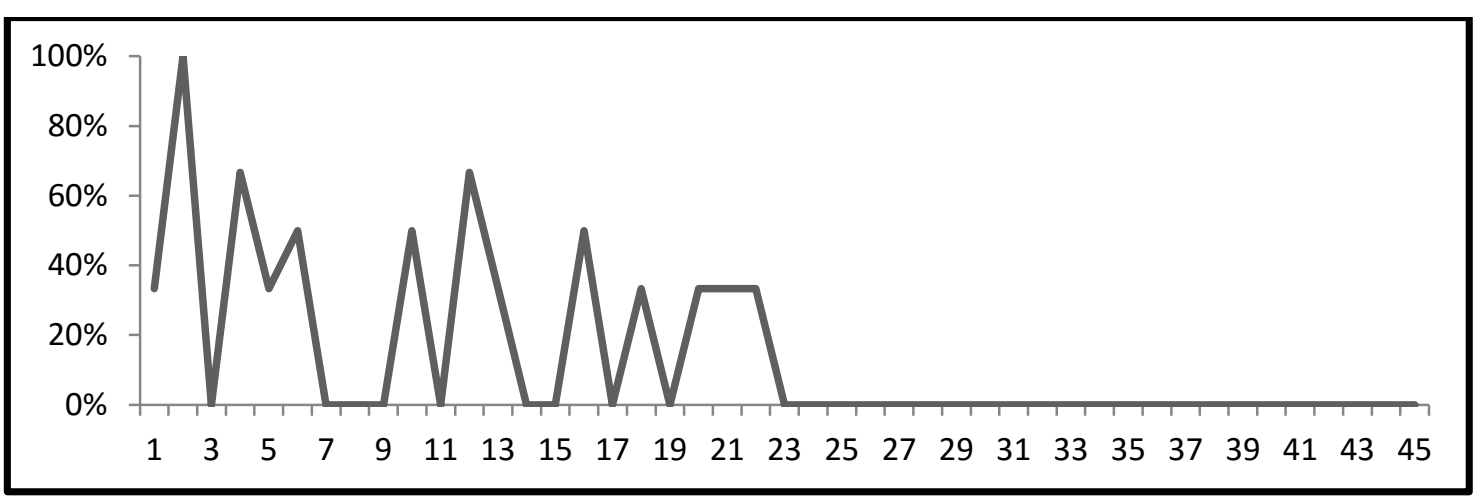

Fonte: DOXA 2012.

\section{b) Rodrigo Maia (DEM)}

\begin{tabular}{|c|c|c|c|}
\hline Frase 1 & Assunto & Duração & Exibição \\
\hline $\begin{array}{c}\text { "Tão importante quanto pensar } \\
\text { no Rio do Futuro, da copa e das } \\
\text { olimpíadas..." }\end{array}$ & Crítica à gestão atual e & 15 segundos & número total de \\
& apresentação de propostas. & & spots do \\
& & & candidato. \\
\hline
\end{tabular}




\begin{tabular}{|c|c|c|c|}
\hline Frase 2 & Assunto & Duração & Exibição \\
\hline $\begin{array}{c}\text { “Quando prefeito, os servidores } \\
\text { tinham acesso...” }\end{array}$ & $\begin{array}{r}\text { Fala do ex-prefeito César } \\
\text { Maia. Comparação com a } \\
\text { gestão atual. }\end{array}$ & 15 segundos & 36 vezes. \\
\hline Frase 3 & Assunto & Duração & Exibição \\
\hline “Mais oportunidades. É isso que & Trabalho e formação & 15 segundos & 38 vezes. \\
\hline nossos jovens precisam...” & profissional. & & \\
\hline
\end{tabular}

Fonte: DOXA 2012.

Total de exibições por tempo

\begin{tabular}{|c|c|}
\hline $\mathbf{1}$ minuto & $\mathbf{1}$ \\
\hline $\mathbf{3 0}$ segundos & 57 \\
\hline $\mathbf{1 5}$ segundos & 520 \\
\hline TOTAL & 578 \\
\hline
\end{tabular}

Fonte: DOXA 2012.

Rodrigo Maia utilizou apenas 1 inserção de 1 minuto que afirmava que "O Rio tá bombando para algumas construtoras". Do total de 578 inserções, 9,8\% foram de 30 segundos e 89,9\% de 15 segundos. Todos os ataques foram direcionados a Eduardo Paes, o que compreendeu o objetivo de $23,8 \%$ de suas inserções. $14 \%$ foram dedicadas a estabelecer comparações entre o governo de Eduardo Paes e os mandatos de César Maia, a maioria delas apresentadas pelo ex-prefeito. Grande parte dos ataques foram feitos na primeira metade da campanha e se referiam, em sua maioria, à saúde e transporte público. 
Gráfico 3 - Ataques de Maia direcionados a Paes/dia

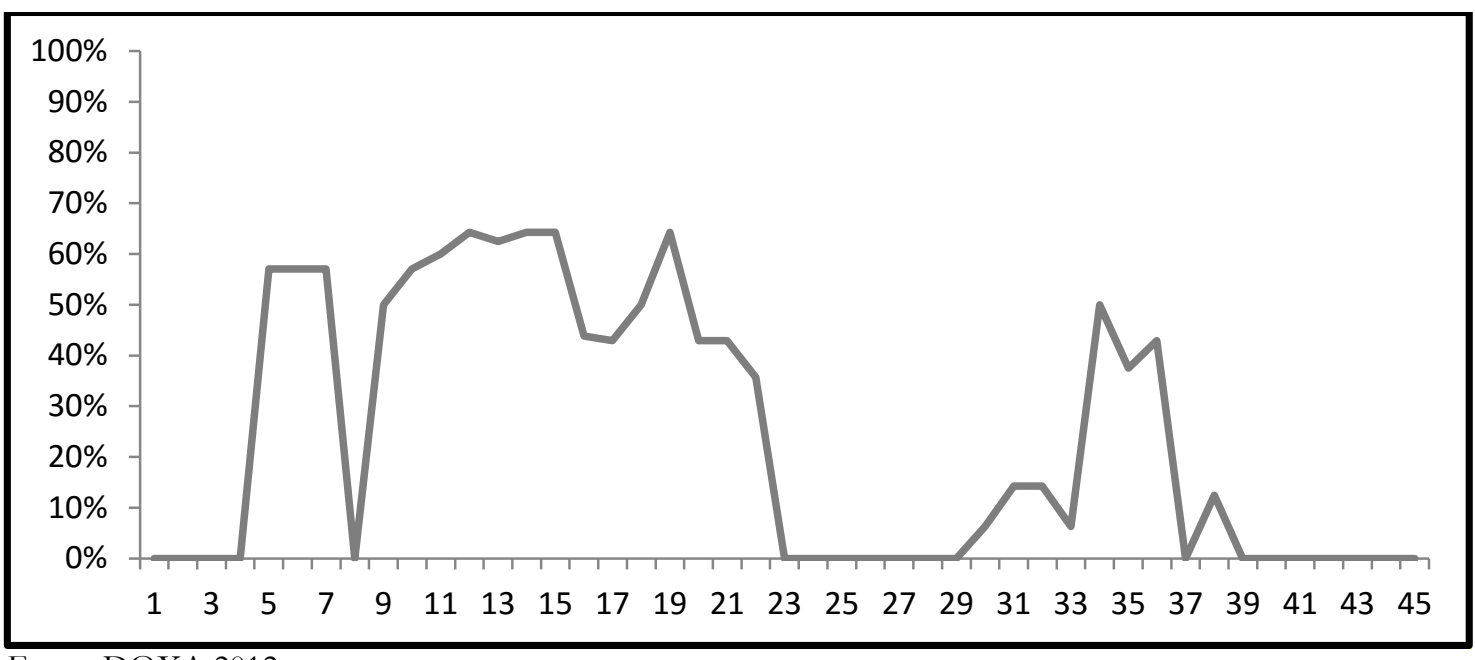

Fonte: DOXA 2012.

d) Otávio Leite (PSDB)

\begin{tabular}{|c|c|c|c|}
\hline Frase 1 & Assunto & Duração & Exibição \\
\hline $\begin{array}{c}\text { “Educação pública de } \\
\text { qualidade passa por um } \\
\text { profissional de educação } \\
\text { prestigiado e respeitado, plano } \\
\text { de cargos, salários dignos e } \\
\text { formação continuada são meus } \\
\text { compromissos com vocês...” }\end{array}$ & $\begin{array}{l}\text { Valorização do profissional de } \\
\text { educação. }\end{array}$ & 15 segundos & 37 vezes. \\
\hline Frase 2 & Assunto & Duração & Exibição \\
\hline $\begin{array}{c}\text { “Eu quero convocar } \\
\text { todos vocês: deficientes, } \\
\text { familiares e amigos para uma } \\
\text { grande mobilização. Agora é } \\
\text { que as pessoas decidem o } \\
\text { voto...” }\end{array}$ & $\begin{array}{l}\text { Pedido de voto e de mobilização } \\
\text { de convencimento. }\end{array}$ & 15 segundos & 34 vezes. \\
\hline Frase 3 & Assunto & Duração & Exibição \\
\hline $\begin{array}{l}\text { “Gastar um bilhão e } \\
\text { meio, o equivalente a três } \\
\text { cidades da música, para } \\
\text { derrubar a perimetral é um } \\
\text { absurdo..." }\end{array}$ & $\begin{array}{l}\text { Manifestação de } \\
\text { contrariedade ao projeto } \\
\text { apresentado pela situação de } \\
\text { derrubar o viaduto da } \\
\text { perimetral. }\end{array}$ & 15 segundos & 31 vezes. \\
\hline
\end{tabular}

Fonte: DOXA 2012. 
Total de exibições por tempo

\begin{tabular}{|l|l|}
\hline $\mathbf{1}$ minuto & $\mathbf{0}$ \\
\hline $\mathbf{3 0}$ segundos & 0 \\
\hline $\mathbf{1 5}$ segundos & 588 \\
\hline TOTAL & 588 \\
\hline
\end{tabular}

Fonte: DOXA 2012.

Otávio Leite optou por dividir todo o seu tempo disponível em inserções rápidas de 15 segundos, totalizando 588. Dentre elas 19,7\% foram ataques, direcionados ao candidato Eduardo Paes, a maioria deles referente à saúde e educação.

Gráfico 4 - Ataques de Otávio Leite direcionados a Paes/dia

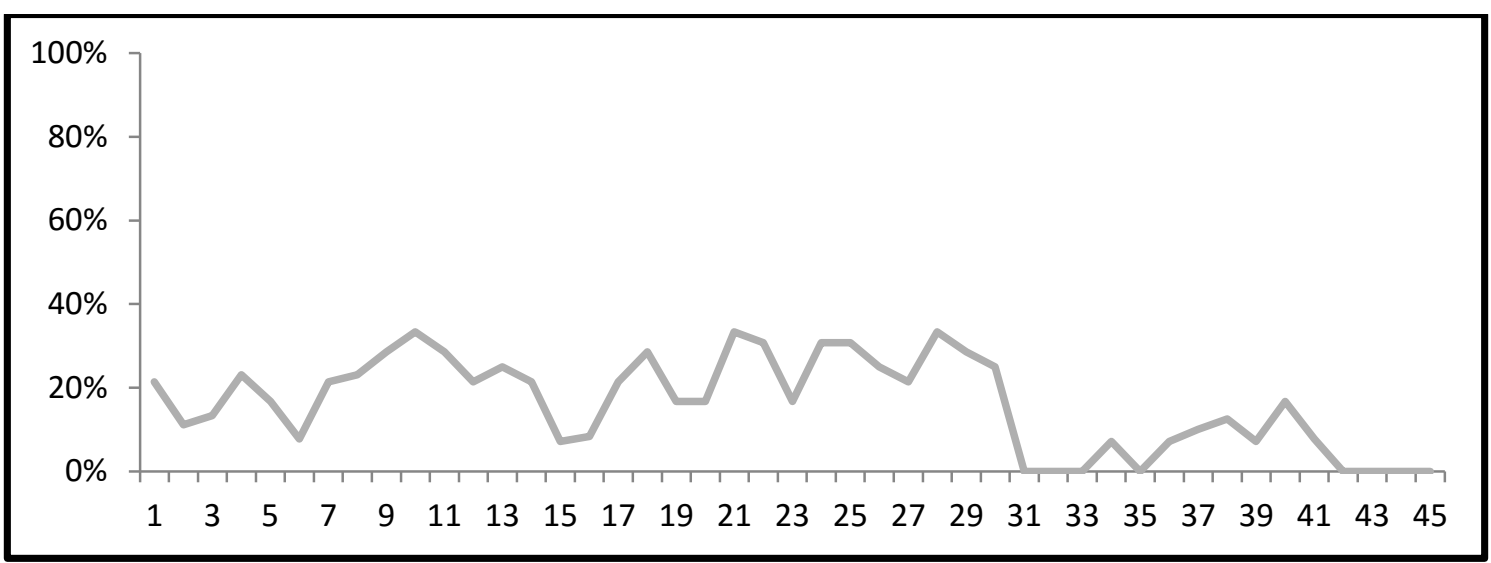

Fonte: DOXA 2012.

e) Aspásia (PV)

\begin{tabular}{|c|c|c|c|}
\hline Frase 1 & Assunto & Duração & Exibição \\
\hline $\begin{array}{l}\text { "Em } 2010 \text { vinte milhões de } \\
\text { brasileiros votaram pela } \\
\text { sustentabilidade" } \\
\text { Assunto: Referência à campanha } \\
\text { de Marina Silva (PV) para a } \\
\text { presidência em } 2010 \text {. }\end{array}$ & $\begin{array}{l}\text { Referência à campanha } \\
\text { de Marina Silva (PV) para a } \\
\text { presidência em } 2010 \text {. }\end{array}$ & 15 segundos & 50 vezes. \\
\hline Frase 2 & Assunto & Duração & Exibição \\
\hline $\begin{array}{l}\text { "Quero ser Prefeita porque } \\
\text { tenho ideias novas e variáveis..." }\end{array}$ & $\begin{array}{l}\text { Pedido de voto. } \\
\text { Trajetória política. }\end{array}$ & 30 segundos & 19 vezes. \\
\hline Frase 3 & Assunto & Duração & Exibição \\
\hline
\end{tabular}




\begin{tabular}{|l|c|c|c|}
\hline $\begin{array}{l}\text { "As mulheres são maioria na } \\
\text { cidade do Rio de Janeiro" }\end{array}$ & $\begin{array}{c}\text { Pedido de voto. Representação } \\
\text { feminina. }\end{array}$ & 30 segundos & 16 vezes. \\
\hline
\end{tabular}

Fonte: DOXA 2012.

Total de exibições por tempo

\begin{tabular}{|l|l|}
\hline $\mathbf{1}$ minuto & $\mathbf{0}$ \\
\hline $\mathbf{3 0}$ segundos & 124 \\
\hline $\mathbf{1 5}$ segundos & 50 \\
\hline TOTAL & 174 \\
\hline
\end{tabular}

Fonte: DOXA 2012.

\section{f) Cyro Garcia (PSTU)}

\begin{tabular}{|c|c|c|c|}
\hline Frase 1 & Assunto & Duração & Exibição \\
\hline $\begin{array}{l}\text { "Transporte público no Rio é o } \\
\text { caos..." }\end{array}$ & $\begin{array}{l}\text { Transporte público. Critica ao } \\
\text { governo de Eduardo Paes. }\end{array}$ & 15 segundos & 44 vezes. \\
\hline Frase 2 & Assunto & Duração & Exibição \\
\hline $\begin{array}{c}\text { “A educação pública no Rio é um } \\
\text { desastre..." }\end{array}$ & $\begin{array}{l}\text { Educação. Crítica ao governo de } \\
\text { Eduardo Paes. }\end{array}$ & 15 segundos & 26 vezes. \\
\hline Frase 3 & Assunto & Duração & Exibição \\
\hline $\begin{array}{l}\text { "Os candidatos dos ricos mentem } \\
\text { quando dizem que existe } \\
\text { democracia nas eleições. Que } \\
\text { democracia é essa que um } \\
\text { candidato tem } 16 \text { minutos na TV, } \\
\text { enquanto nós do PSTU temos } \\
\text { apenas } 60 \text { segundos..." }\end{array}$ & $\begin{array}{l}\text { Crítica à regra de distribuição de } \\
\text { tempo de TV. }\end{array}$ & 15 segundos & 25 vezes. \\
\hline
\end{tabular}

Fonte: DOXA 2012.

Total de exibições por tempo

\begin{tabular}{|l|l|}
\hline $\mathbf{1}$ minuto & $\mathbf{0}$ \\
\hline $\mathbf{3 0}$ segundos & 47 \\
\hline $\mathbf{1 5}$ segundos & 123 \\
\hline TOTAL & 170 \\
\hline
\end{tabular}

Fonte: DOXA 2012. 


\section{f) Fernando Siqueira (PPL)}

\begin{tabular}{|c|c|c|c|}
\hline Frase 1 & Assunto & Duração & Exibição \\
\hline $\begin{array}{c}\text { "Olha, em matéria de } \\
\text { transporte o Rio está com } \\
\text { cem anos de atraso..." }\end{array}$ & público. Crítica à situação. & 30 segundos & \\
\hline Frase 2 & Assunto & Duração & Exibição \\
\hline "Você tem acompanhada \\
nossa campanha na TV..."
\end{tabular}

Fonte: DOXA 2012.

Total de exibições por tempo

\begin{tabular}{|l|l|}
\hline $\mathbf{1}$ minuto & $\mathbf{0}$ \\
\hline $\mathbf{3 0}$ segundos & 107 \\
\hline $\mathbf{1 5}$ segundos & 0 \\
\hline TOTAL & 107 \\
\hline
\end{tabular}

Fonte: DOXA 2012.

Dentre os três últimos candidatos apresentados, Aspásia Camargo (PV) manteve uma postura moderada, não exibiu spots de ataque e optou por pedir votos usando argumentos sobre sua trajetória política, preservação do meio ambiente e sobre a importância da representação feminina. A equipe de campanha do candidato Ciro Garcia (PSTU) optou por uma posição de ataque, todos os spots foram dedicados a criticar o governo vigente e, talvez devido à escassez de tempo, nenhuma proposta concreta foi apresentada. Fernando Siqueira (PPL), era o candidato menos conhecido pelos eleitores, segundo as pesquisas de opinião apresentadas pelo Ibope e DataFolha, A equipe do candidato optou por ressaltar sua trajetória no movimento sindical e, em spots de 30 segundos, alternar entre pedido de votos e crítica ao governo vigente.

Quanto ao tempo de inserção, em resumo, os candidatos dividiram seu tempo disponível da seguinte forma: 
Gráfico 5 - Tempo das inserções/ candidato

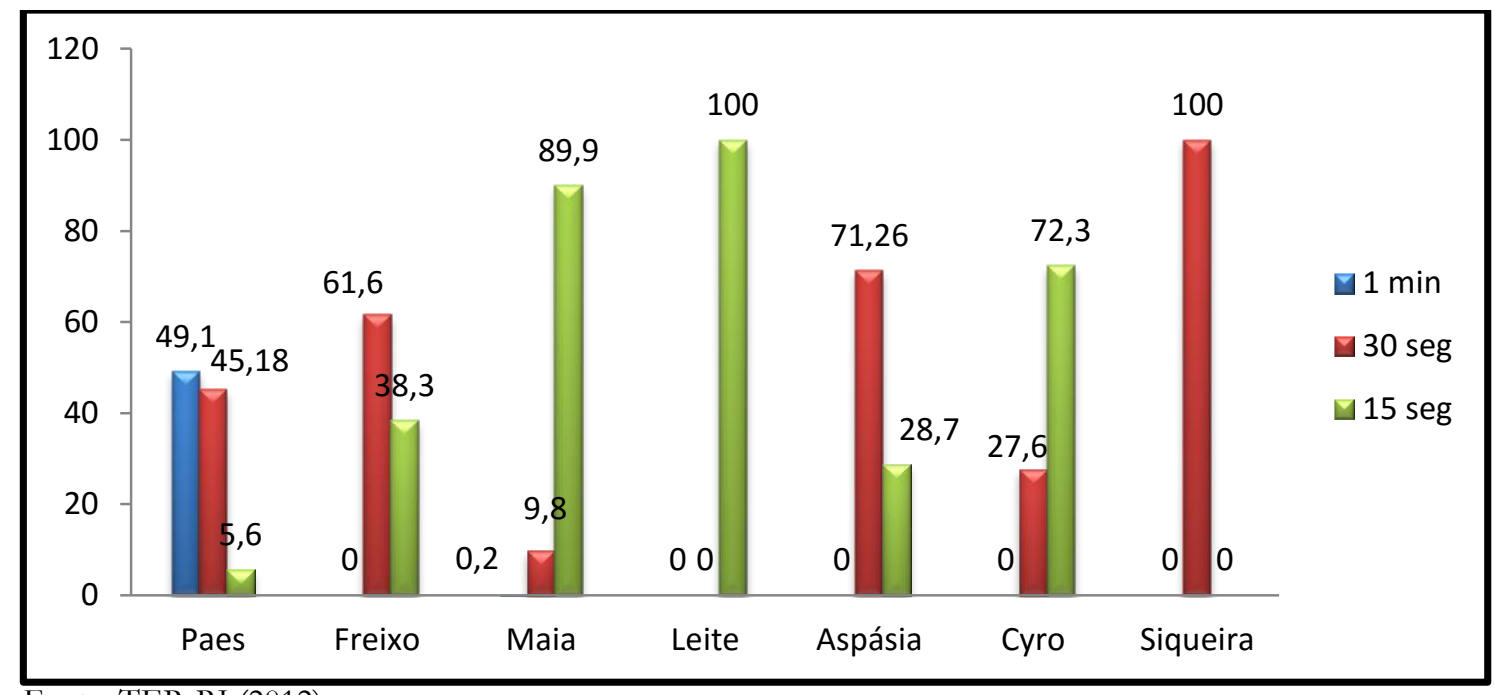

Esse gráfico mostra, acima de tudo, as disparidades da verba de campanha dos candidatos. Eduardo Paes apresentou 490 inserções de 1 minuto, Rodrigo Maia utilizou apenas 1 e os demais candidatos não utilizaram nenhuma. Com o amplo tempo disponível, Paes teve mais facilidade em apresentar suas propostas e persuadir os eleitores. Os objetivos das inserções vinculadas ao longo da campanha podem ser classificados da seguinte forma:

Tabela 2 - Objetivo das inserções

\begin{tabular}{c|c|c|c}
\hline \hline & POSITIVO & NEGATIVO & COMPARAÇÃO \\
\hline Eduardo Paes & 100 & 0 & 0 \\
\hline Marcelo Freixo & 73,3 & 26,6 & 0 \\
\hline Rodrigo Maia & 62,1 & 23,8 & 14 \\
\hline Otávio Leite & 80,2 & 19,7 & 0 \\
\hline Aspásia & 86,2 & 13,7 & 0 \\
\hline Cyro Garcia & 26 & 73,9 & 0 \\
\hline Fernando Siqueira & 39,3 & 60,6 & 0 \\
\hline \hline
\end{tabular}

Fonte: DOXA 2012.

Eduardo Paes exibiu 41 spots diferentes e, em ambos, não fez críticas aos seus adversários, sua estratégia de persuasão foi convencer o eleitor de que o cenário atual está bom e que pode ficar ainda melhor com a sua permanência no governo. O tema mais recorrente nas inserções foi o BRT. Durante suas inserções na TV, rádio e seu programa no HGPE, Paes contou com a presença da presidenta Dilma Rousseff, do governador do estado 
do Rio de Janeiro, Sérgio Cabral Filho e de outros políticos influentes que afirmaram sua parceria com Eduardo Paes em prol do Rio de Janeiro, ressaltando o slogan "Somos um Rio".

O caminho escolhido nesse artigo, de priorizar a análise das inserções de TV ajuda a evidenciar os temas priorizados pela equipe de campanha eleitoral de Eduardo Paes, que foram: educação, transporte público e saúde. Temas recorrentes em todas as pesquisas de opinião pública. Como mostram os dados, o candidato optou por não agredir os outros candidatos, usando todo o seu tempo para ressaltar o que foi construído em seu primeiro mandato e falar sobre a necessidade de continuidade desse projeto.

Analisando o processo eleitoral através da teoria da escolha racional, que parte do pressuposto de que as pessoas são racionais ${ }^{12}$ e agem intencionalmente, calculando os custos e benefícios de cada ação antes de decidirem, maximizando seus ganhos, é possível afirmar que os políticos agem motivados pela busca de prestígio, poder e renda, desenvolvendo, para este fim, ações que visam à maximização de seu apoio, promovendo políticas orientadas para esta finalidade. Os eleitores, por sua vez, estão interessados em fazer a melhor escolha possível com o menor custo. O princípio da racionalidade do comportamento político, presente na teoria da escolha racional, defende que eleitores, candidatos e partidos agem em benefício próprio. Para Downs (1999) o que interessa a esses atores sociais é a maximização dos ganhos, sejam em votos ou outros benefícios. Nessa perspectiva, a campanha eleitoral de Eduardo Paes ofereceu ao eleitor o menor custo de obtenção de informações, pois dispunha de um amplo espaço para divulgar suas realizações anteriores e projetos de continuidade, sem que o eleitor precisasse fazer pesquisas. $O$ teor de seu discurso afirmava que o eleitor votaria em um projeto já bem-sucedido, apresentando-se como a escolha mais racional dentre as outras opções incertas.

No entanto, essa teoria não pode ser generalizada, é válido ressaltar que nem sempre uma escolha racional é tomada. Como destacam Ratton Junior \& Morais (2003): "Uma das maneiras de ler o mapa das motivações humanas seria classificando-as da seguinte forma: às vezes as pessoas perseguem seus objetivos agindo racionalmente; outras, impulsionadas por suas emoções; outras tantas, seguindo normas sociais" (p.387).

\footnotetext{
12 Um indivíduo racional para Downs se comporta da seguinte forma:

1- Ele sempre pode tomar uma decisão quando confrontado com uma série de alternativas;

2- Ele classifica todas as alternativas na ordem de sua preferência, de maneira que cada uma é preferida, indiferente ou inferior a cada uma das outras;

3- Seu ranking de preferência é transitivo;

4- Ele sempre escolhe entre todas as alternativas possíveis, aquela que fica em primeiro lugar no ranking ordenado de preferência; e

5- Ele sempre toma a mesma decisão quando é confrontado com as mesmas alternativas (DOWNS, 1999, p.6).
} 


\section{CONSIDERAÇÕES FINAIS}

Para auxiliar o entendimento da reeleição de Eduardo Paes, é necessário considerar a forma como o candidato articulou as realizações do seu primeiro mandato em suas propagandas eleitorais. Contando com uma boa equipe de marketing o candidato teve 3 minutos a mais do que a somatória do tempo de todos os seus oponentes para persuadir o eleitor, convencendo boa parte deles de que a situação atual estava boa e que iria ficar ainda melhor. Paes soube fazer um resgate de sua trajetória pessoal e associá-la à gestão na prefeitura, que foi bem avaliada pelos eleitores, nas pesquisas de opinião, e também as realizações do governo do Estado, devido a sua parceria com Sérgio Cabral Filho.

Quanto ao cerne dos debates travados entre as campanhas, é possível dizer que o candidato Eduardo Paes não entrou em embates com outros candidatos, limitando os confrontos a respostas em debates realizados na TV e rádio. Os demais candidatos o atacaram, mas não obtiveram reação significativa.

O início do HGPE não trouxe nenhum impacto negativo para o candidato Eduardo Paes (ver anexos 1 e 2). Como descreve Cervi (2010), em casos como esse é como se o HGPE consolidasse decisões já tomadas anteriormente pelo eleitorado. "Por isso, é mais produtivo pensar o horário eleitoral como mais um elemento da disputa política, a partir do qual se pode identificar discursos, posições e escolhas adotadas pela elite política, mas não é suficiente para explicar a decisão do voto" (Cervi, 2010, p.16). Embora não seja suficiente para explicar o resultado das eleições, a campanha de TV das eleições de 2012 teve um papel de destaque e consolidação. Tanto pela quantidade de tempo que o candidato dispunha, superior a soma do tempo de todos os outros candidatos, mas também pelos discursos, posições e escolhas que a equipe de campanha adotou.

Podemos afirmar que um dos principais fatores que garantiram a vitória expressiva de Eduardo Paes se baseia no que Downs (1999), Fiorina (1991), Catt (1996) e Carreirão (2002) chamaram de voto retrospectivo. De acordo com esse conceito, o eleitor realiza uma comparação sobre o desempenho governamental e o compara com as propostas do candidato opositor, se a avaliação for positiva o eleitor vota no candidato da situação; sendo esta avaliação negativa o eleitor vota na oposição. A campanha de Paes calcada nas realizações da gestão anterior, que dispunha de apenas 15\% de rejeição, fez com que o eleitor, partindo de uma boa avaliação do mandato anterior, utilizasse o passado para projetar o futuro e escolher o seu candidato. 


\section{REFERÊNCIAS}

CARREIRÃO, Y. de S. A decisão do voto nas eleições presidenciais brasileiras. Rio de Janeiro: FGV; Florianópolis: Edufsc, 2002.

CATT, H.Voting behavior: a radical critique. London: Leicester University Press, 1996.

CERVI, E. U. O “tempo da política” e distribuição dos recursos partidários: uma análise do HGPE. Em Debate, Belo Horizonte, v.2, n.8, p. 12-17, ago. 2010.

Código Eleitoral Anotado. Disponível em: http://www.tse.jus.br/hotSites/CatalogoPublicacoes/pdf/codigo_eleitoral_2012/TSECodigo-Eleitoral-2012-Web.pdf. Acesso em: 29-03-2013.

DATAFOLHA http://datafolha.folha.uol.com.br. Acesso em: 29-03-2013.

DOWNS, A. Uma teoria econômica da democracia. São Paulo. Edusp, 1999.

FIGUEIREDO, M.; ALDÉ, A.; DIAS, H. \& JORGE, W. Estratégias de Persuasão em Eleições Majoritárias: Uma Proposta Metodológica para o Estudo da Propaganda Eleitoral. Disponível em: http://doxa.iesp.uerj.br/artigos/SE100.pdf. Acesso em: 29-032013.

FIORINA, M. Retrospective voting in American nacional elections. New Haven: Yale University Press, 1981.

IBOPE. Disponível em: http://www.eleicoes.ibope.com.br. Acesso em: 29-03-2013.

Lei das Eleições. Disponível em: http://www.tse.jus.br/legislacao/codigo-eleitoral/lei-daseleicoes/lei-das-eleicoes-lei-nb0-9.504-de-30-de-setembro-de-1997. Acesso em: 29-03-2013.

RATTON JUNIOR, J. L. de A.; MORAIS, J. V. de. Para Ler Jon Elster: Limites e possibilidades da explicação por mecanismos nas Ciências Sociais. DADOS - Revista de Ciências Sociais, Rio de Janeiro, Vol. 46, n²2, 2003, pp.385-410. 
ANEXO 1

Pesquisa de intenção de voto IBOPE - Estimulada (2012)

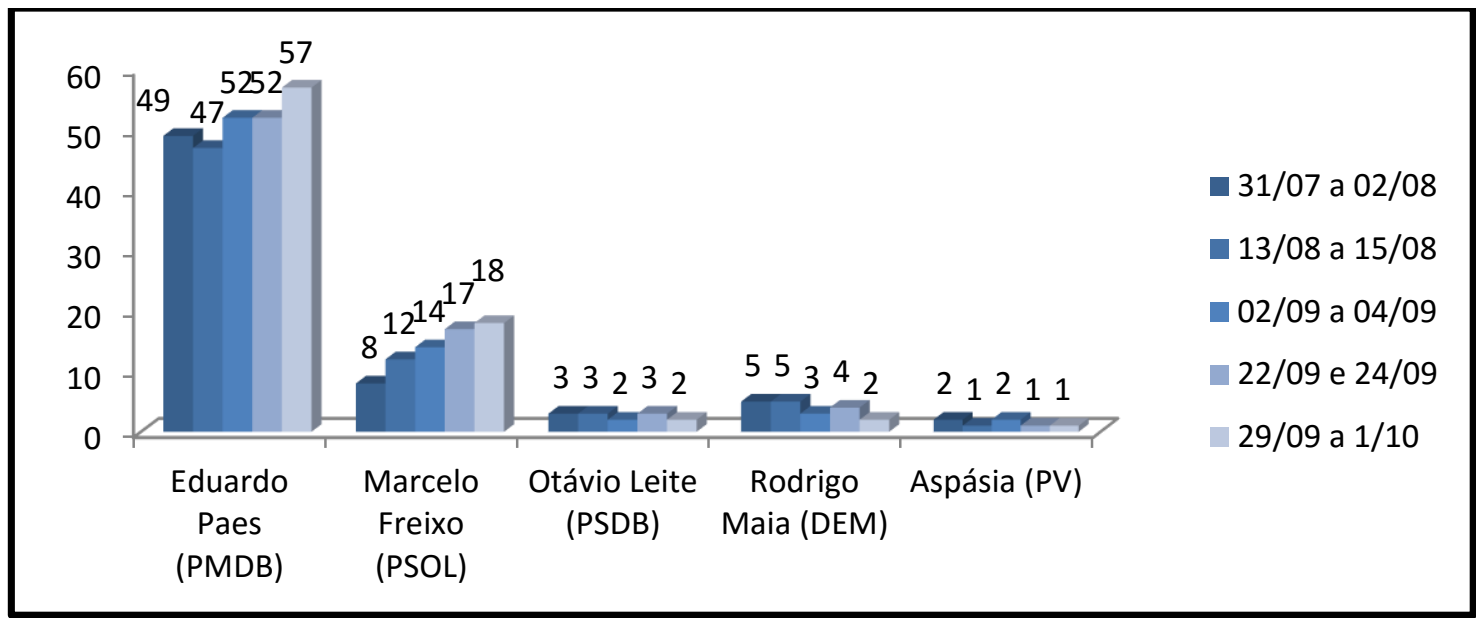

Fonte: IBOPE 2012

ANEXO 2

Pesquisa de intenção de voto Datafolha - Estimulada (2012)

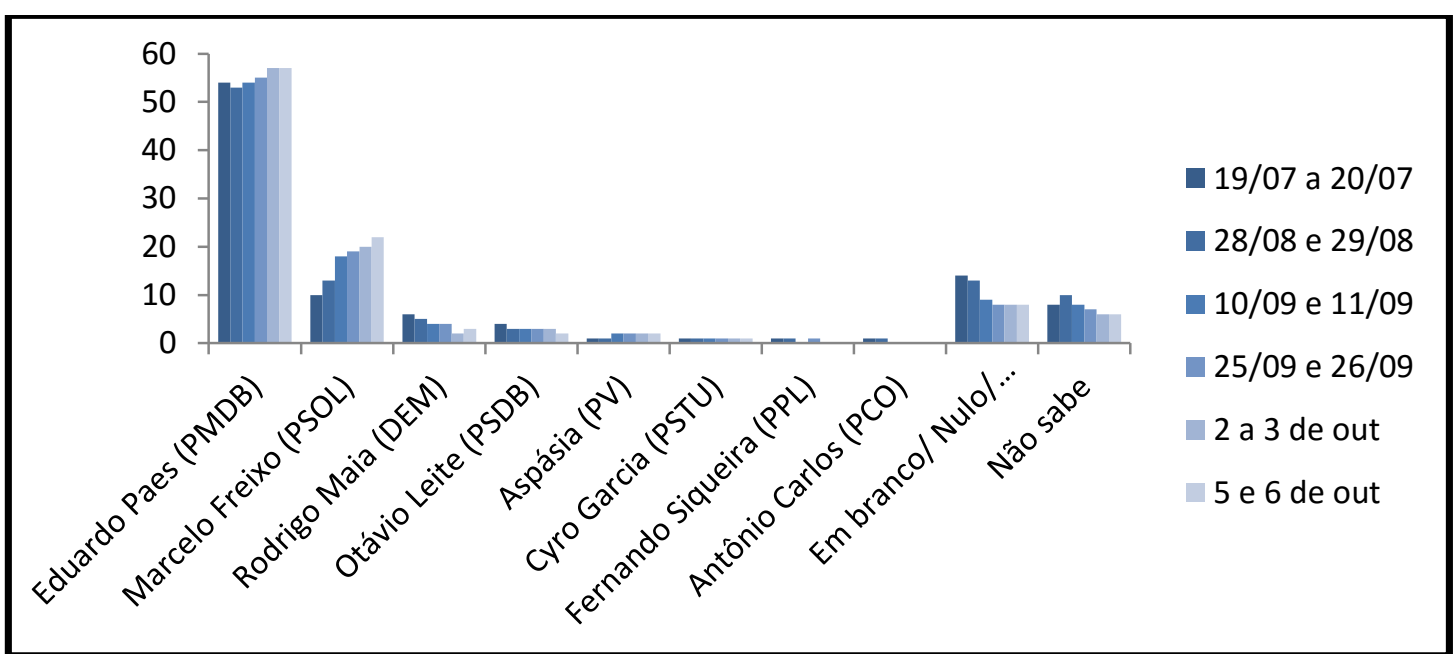

Fonte: Datafolha (2012) 